\title{
ETHAVERINE IN THE TREATMENT OF ANGINA PECTORIS
}

BY

\author{
D. P. DEGENHARDT AND ROBERT HODGKINSON
}

From the West Middlesex Hospital and the Department of Clinical Investigation (London), Parke, Davis \& Company Ltd.

Received September 16, 1953

Papaverine and its analogues have been advocated by a number of authors for the treatment of angina pectoris, and this study describes an attempt to evaluate the ethyl analogue of papaverine, ethaverine (diquinol) for this purpose. The relationship of ethaverine to papaverine and dioxyline phosphate (pavaril) is shown below.

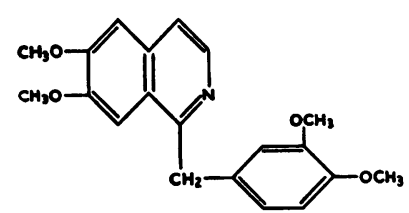

Papaverıne

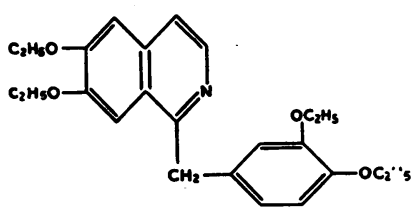

Ethaverine

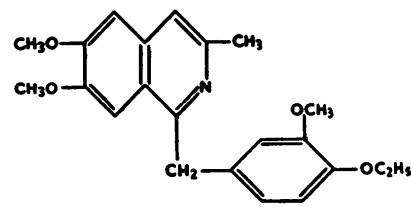

Dioxyline phosphate

Following the successful use of intravenous papaverine in a case of angina by Pal (1913), Macht (1916) described its powerful dilator action on the coronary arteries of the frog, and this was confirmed in dogs by Essex (1940). Both dioxyline phosphate and ethaverine have been shown to equal papaverine in their dilating effect on the coronary arteries of dogs (Winder et al., 1950; Henderson et al., 1951); the effect of ethaverine was, however, found to be slower in onset and its action more prolonged.

The clinical evidence for the effectiveness of papaverine and its derivatives in the relief of angina pectoris is, however, less decisive. Pal (1913 and 1922), Macht (1916), Boehm (1921), Kohn (1920), and Dopffel and Kutshera-Aichberger (1940) described the alleviation by papaverine of the pain of angina. The first controlled trial in which its action was compared with that of other drugs, as well as with a placebo, was by Evans and Hoyle (1933) whose results suggested that the drug was effective but the statistical significance of their findings was doubtful. Katz and Elek (1943) also found that in 12 of 17 patients the symptoms of angina were relieved, but a further study by the same group of workers (Simon et al., 1949), using a double blind technique, concluded that papaverine was of only limited value in the treatment of angina. Gray et al. (1945) also found little value in its oral administration but showed that some clinical improvement followed its intravenous use. Russek et al. (1950) using a double blind technique showed that papaverine modified the changes in the electrocardiogram following a standardized amount of exercise.

Of the papaverine derivatives, dioxyline phosphate was found by Frisch et al. (1952) to have no effect on the symptoms of the disease, but some retinal arteriolar dilatation was shown by the flicker-photometer. Best and Coe (1951), however, using a double blind technique, showed symptomatic improvement in 5 of 11 patients, whilst the cardiogram showed less abnormalities when dioxyline was given in addition to exercise than when exercise was taken alone. A further paper by Myers et al. (1952), showed that excellent relief was noted by 9 , good relief by 6 , and fair relief by 3 
of 25 patients. In all these trials with dioxyline phosphate a dosage of between 600 and $1200 \mathrm{mg}$. a day were given orally.

The marked coronary dilating activity of ethaverine in laboratory studies, the clinical studies on the action of papaverine and its derivatives in angina, together with its low toxicity, suggested a clinical trial of ethaverine in the treatment of angina pectoris. Its previous clinical use had been confined to spastic conditions of the intestinal, biliary, and urinary tracts (Adler, 1932; Goldstein, 1937; Ionescu-Militiade, 1932; Kottlors, 1934; Szentkiralyi, 1932), to dysmenorrhœa (Wiesbader, 1933), and to hypertension (Dobrzanski, 1935; Spychala, 1934). No evidence of toxicity was noted in these trials. Berkesy (1932) described ethaverine as non-toxic and free from local irritation, even on subcutaneous injection. Dobrzanski (1935) remarked on its low toxicity, whilst Spychala (1934) described it as being two to three times less toxic than papaverine.

\section{METHOD}

Twenty-two patients suffering from angina of effort were treated during this trial. All described the characteristic pain of short duration brought on by exercise and relieved by rest and nitrites. Their ages ranged from 43 to 68, and the duration of symptoms was between one and six years in all except four patients. The blood pressure exceeded $170 / 100$ in 18 , and was above normal in all cases. The Wassermann reaction was negative, and the hæmatological findings within normal limits in the whole series. Electrocardiograms were recorded for each patient before and after exercise; the exercise consisting of walking up and down two steps until pain was produced. Three patients had evidence of previous myocardial infarction and a further three showed bundle branch block. Nine patients had typical patterns of coronary insufficiency in the cardiogram with no definite evidence of infarction. Some of these showed further abnormalities after exercise. Four others had normal cardiograms at rest but showed alterations in the S-T segment after exercise. Attempts were made throughout the study to challenge the diagnosis and also the suitability of the patient for inclusion in this trial. All patients were ambulatory. One patient was excluded from the final analysis because she had an attack of severe precordial pain after five days' treatment with ethaverine, and treatment was stopped at her own request. Another failed to attend the clinic regularly. This left 20 patients who completed the trial and were available for analysis.

Two materials were compared-50-mg. capsules of ethaverine and indistinguishable capsules of lactose as controls. A dosage of two capsules four times daily ( $400 \mathrm{mg}$. of ethaverine daily) was employed, and the capsules were supplied in bottles each containing one week's supply. All patients received six pairs of bottles, numbered 1 to 6 , to be taken consecutively, and of these, three contained ethaverine and three lactose. The pairs of bottles were mixed at random, and could only be identified by means of a cipher which was kept in a sealed envelope until the completion of the trial. Neither patient nor doctor knew the identity of the capsules. After twelve weeks' therapy some patients received further supplies of the capsules, but this time four-weekly periods were used instead of fortnightly.

A subjective evaluation was carried out by use of a daily report card on which the patient indicated by a cross the degree of pain he had during the day. No account was taken of weather changes, of mental stress, or of changes in habit, and the patient was allowed to take tablets of glyceryl trinitrate as required. (It was considered that as the patient acts as his own control the effect of these factors should, after an adequate period of time, cancel each other out and also as each patient received the capsules in a different order for the same period weather changes could also be neglected.)

Objective evaluation was attempted by the exercise tolerance test on those patients considered to be sufficiently well. After a half-hour rest the patient walked up and down two steps (Master et al., 1944) until the first symptoms of pain developed, and the number of trips over the steps was recorded. Some of the patients were considered to be too ill or became too breathless to be subjected to exercise, and if any patient had suffered from an attack of angina during the hour prior to attending the clinic no test was undertaken at that visit. 


\section{RESULTS}

Analysis of the daily report cards over the whole period of the trial (1517 days on ethaverine and 1487 days on placebo treatment) showed that while on treatment with ethaverine the patients reported 14.2 per cent of days free from pain, 44.4 per cent good days, 36 per cent average days, 5.4 per cent bad days, whilst during treatment with the control capsules they reported 13.1 per cent of days free from pain, 44.4 per cent good days, 36.3 per cent average days, and $6 \cdot 2$ per cent bad days. These results show no significant difference.

As approximate blood levels obtained by a photospectrometric technique showed the presence of ethaverine or a derivative in substantial amounts twenty-four hours after administration of three capsules, it was considered that there would be an accumulation of the drug in the blood. To allow for the cumulative effect the second week of treatment period of either lactose or ethaverine was analyzed apart from the first week. The result of this analysis showed no greater difference between periods of treatment and non-treatment than when both weeks were taken together.

Analysis of the exercise tolerance test showed that 932 " trips" were performed at the end of periods of ethaverine treatment, whilst 990 " trips" were performed after periods of control treatment (Table I). No side-effects attributed to the drug were noted during the trial.

TABLE I

Comparison of Exercise Tolerance after Courses of Ethaverine and after Courses of Control Capsules

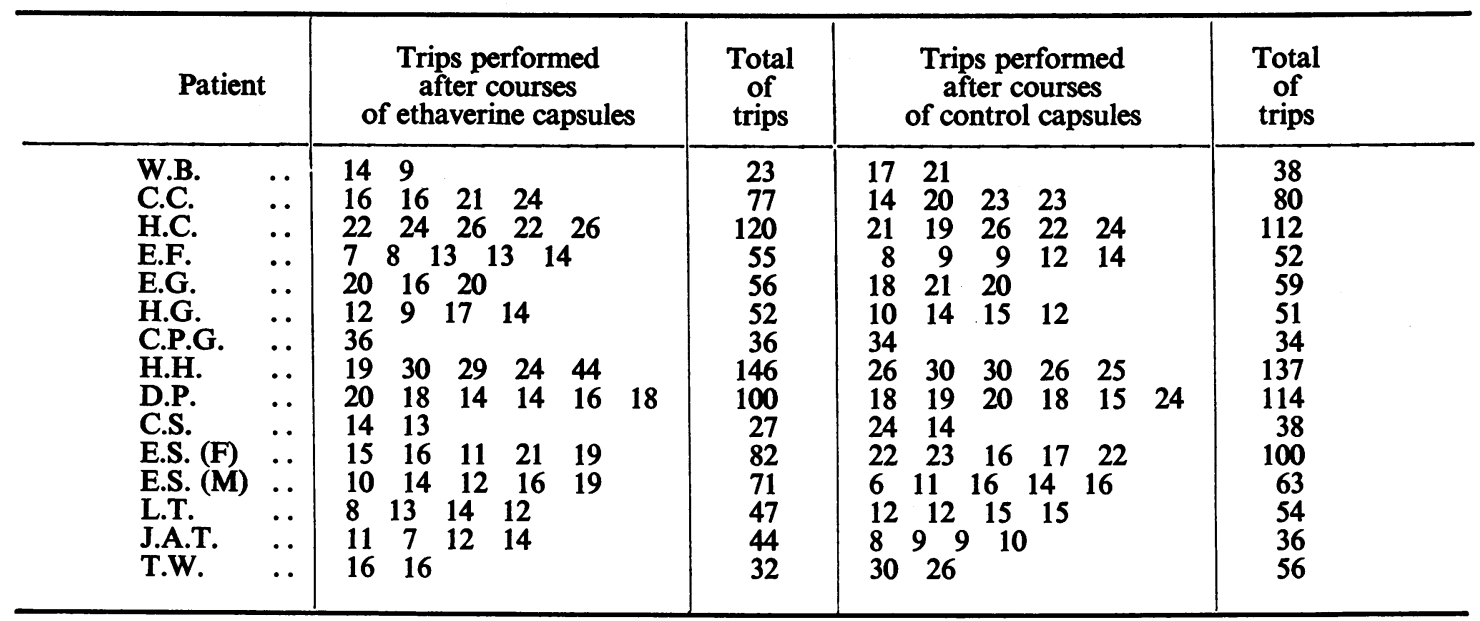

Total of trips performed after ethaverine $=932 . \quad$ Total of trips performed after control capsules $=\mathbf{9 9 0}$.

\section{Conclusions}

Under the conditions of the trial ethaverine had no greater effect than inert lactose control capsules on the prevention of pain due to angina of effort. Occasionally patients showed apparent marked improvement on ethaverine, but an approximately equal number showed a similar change on control capsules. No common characteristic marked those showing improvement.

Analysis at the end of three months' treatment showed substantially the same results as the final analysis. It is felt that any drug with a marked effect in angina pectoris should show its effect in three months, and this period was considered to be sufficient for a future preliminary assessment of a drug at one dosage level.

In spite of these negative results it was interesting to note that many of the patients claimed great benefit from the use of the capsules, whether drug or control. This emphasizes the importance of the "double blind method" for evaluation of a drug. Incidentally, it was found that the drug had no effect on the incidence of intermittent claudication in two patients, nor did it have any effect on the blood pressure of any of the patients. 


\section{Discussion}

Evans and Hoyle, in 1933, stated in regard to the treatment of angina pectoris, "there has scarcely been a methodical attempt to compare relative values of the many drugs that have been recommended, and uncontrolled and isolated observations have too often guided opinions." A number of improvements have since been made in the method of assessing the value of drugs in treatment. The most important of these has probably been the use of active and placebo capsules or tablets which are identical in appearance and the use of the double blind technique in diseases on which suggestion alone will produce dramatic results.

The exercise tolerance test (Riseman and Stern, 1934; Riseman and Brown, 1937) provides a method for the objective evaluation of the drug capable of dilating the coronary circulation. Since ethaverine appears to remain in the blood stream for over twenty-four hours it was not possible to perform this test twice on the same day using the blind technique. It was also felt that despite the impossibility of performing the test under completely identical circumstances at different visits to the clinic, the advantages of the double blind technique, together with the advantage obtained by testing after two weeks' accumulation of the drug in the blood stream, greatly outweighed the possible disadvantages.

Although the electrocardiogram was altered by exercise in a number of patients, no modification of this change was found following the dose of ethaverine used in this trial (i.e. $400 \mathrm{mg}$. daily). It should, however, be noted that Russek et al. (1950) had to administer over $500 \mathrm{mg}$. of papaverine before the effect on the electrocardiogram was striking. The dosage found necessary by these workers to modify the patterns produced by exercise in cases of angina may explain the failure to obtain clinical improvement of the condition of the patients in this trial.

Subjective evaluation of a drug's usefulness in angina may be carried out by asking the patient at each of his visits to the clinic what progress he has made since he was last seen. There is, however, difficulty in obtaining a brief answer that approaches accuracy, for the patient's memory of his condition some weeks previously is not to be relied on, and a wrong conclusion on the part of the patient will make a large difference to the final result since each decision applies to a week or fortnight. These disadvantages can be minimized by using a daily record, as was used in this trial. Using this method the doctor should remind the patient at frequent intervals that he must record whether he had a good day or a bad day, and that in doing this he should take into account the number of, for instance, glyceryl trinitrate tablets he has consumed or the amount of exercise he has taken. The main objection to this method is that the patient's decision on a good day or bad day is not made against any fixed standard. After three days of no pain, for instance, a day which he would normally describe as a good day may seem to be a very bad day.

The close agreement between the results of the subjective and objective evaluation of ethaverine in this trial makes it improbabie that this drug has any effect at the dosage level used. In view, however, of the repeatedly confirmed action of papaverine and its derivatives on the coronary circulation in experimental animals, the effect of papaverine on the cardiogram in high dosage, as shown by Russek et al. (1950), and the absence of toxicity, a dosage several times greater than we employed may produce beneficial effects on cases of angina pectoris.

\section{SUMMARY}

Under the conditions of this trial ethaverine in a dosage of $400 \mathrm{mg}$. daily was found to have no greater action on the pain experienced or the exercises performed by patients suffering from angina pectoris than inert lactose capsules.

Earlier records on the use of papaverine and its analogues in angina pectoris and methods of evaluating drugs in angina are briefly reviewed.

Evaluation at a higher dosage level, and for longer periods of time, is considered worthy of trial. 
We are grateful for the advice and encouragement given to us by Dr. M. M. Deane, and we wish to thank him and Dr. N. F. Coghill for referring patients to us. We also wish to express our appreciation of the assistance of Mr. J. R. Ritchie at the clinic and in the preparation of this report. We are indebted to Mr. D. Vinten and his staff for recording the electrocardiograms. The ethaverine and placebo capsules used in the trial were given by Messrs. Parke, Davis \& Company, Limited.

\section{REFERENCES}

Adler, S. (1932). Gyogyaszet, 72, 76.

Berkesy, L. (1932). Therap. der Gegenwart, 73, 55.

Best, M. M., and Coe, W. S. (1951). Amer. J. med. Sci., 222, 35.

Boehm, G. (1921). Münch. med. Wschr., 68, 106.

Dobrzanski, C. (1935). Polska Gaz. Lek., 14, 44.

Dopffel, O., and Kutschera-Aichberger, H. (1940). Z. Klin. med., 137, 341.

Elek, S. R., and Katz, L. N. (1942). J. Amer. med. Assoc., 120, 434.

Evans, W., and Hoyle, F. (1934). Quart. J. Med., 3, 105.

Essex, H. E., Wegria, R., Herrick, J. F., and Mann, F. C. (1940). Amer. Heart J., $19,554$.

Frisch, R. A., Kaufman, K. K., Beezy, R., and Garry, M. W. (1952). Amer. J. med. Sci., $224,304$.

Goldstein, H. I. (1937). Rev. Gastroent., 4, 305.

Gray, W., Riseman, J. E. F., and Stearns, S. (1945), New Eng. J. Med., 232, 389.

Greiner, T., Gold, H., Cattell, McK., Travell, J., Bakst, H., Rinzler, S. H., Benjamin, Z. H., Warshaw, L. J., Bobb, A. L., Kwit, N. T., Modell, W., Rothendler, H. H., Messeloff, C. R., and Kramer, M. L. (1950). Amer. J. Med., 9, 143.

Henderson, F. G., Shipley, R. E., and Chen, K. K. (1951). J. Amer. pharm. Ass., 60, 207.

Ionescu-Militiade, I. (1932). Romania Med., 10, 204.

Issekutz, B. V., Leinzinger, M., and Dirner, Z. (1932). $\quad$ Arch. exper. Path. Pharmakol, $164,158$.

Katz, L. N., and Elek, S. R. (1943). J. Amer. med. Assoc., 122, 196.

Kohn, H. (1929). Ztschr. arztl. Fortbild., 26, 790.

Kottlors, E. (1934). Med. Klinik., 30, 1498.

Krasno, L. R., and Ivy, A. C. (1950). Circulation, 1, 1267.

Macht, D. I. (1916). Arch. intern. Med., 17, 768.

Master, A. M., Nuzic, S., Brown, R. C., and Parker, R. C. (1944). Amer. J. med. Sci., 207, 435.

Meyer, J. M., Correll, H. L., Peters, B. J., and Lindert, M. C. F. (1952). Amer. Pract., 3, 379.

Pal, J. (1913). Dtsch. med. Wschr., 2, 2068.

(1923), Wien. Arch. inn. Med., 6, 153.

Pouchet, M. G. (1933). Bull. Acad. Méd., Paris, 3, ser. 110, 724.

Riseman, J. E. F., and Brown, M. G. (1937). Arch. intern. Med., 60, 100.

- and Stern, B. (1934). Amer. J. med. Sci., 188, 646.

Russek, H. I., Smith, R. H., Baum, W. S., Neagele, C. F., and Regan, F. D. (1950). Circulation, 1, 700.

Simon, A. J., Dolcin, M., Solway, A. J. L., Hirschman, J., and Katz, L. N. (1949). J. lab. clin. Med., $34,992$.

Spychala, V. (1934). Polska Gaz. Lek, 13, 677.

Szentkiralyi, Z. (1932). Orvosi Hetilap, 76, 973.

Wiesbader, H. (1933). Klin. Wschr., 12, 106.

Winder, C. V., Thomas, R. W., and Kamm, O. (1950). J. Pharmacol., 100, 482. 